\title{
Safety and efficacy of amphotericin-B deoxycholate inhalation in critically ill patients with respiratory Candida spp. colonization: a retrospective analysis
}

Patrick J van der Geest ${ }^{1 *}$, Erik I Dieters ${ }^{1}$, Bart Rijnders ${ }^{2}$ and Johan AB Groeneveld ${ }^{1}$

\begin{abstract}
Background: Candida spp. are frequently cultured from the respiratory tract in critically ill patients. Most intensivists start amphotericin-B deoxycholate (ABDC) inhalation therapy to eradicate Candida spp. from the respiratory tract. However, the safety and efficacy of this treatment are not well established. The purpose of this study was to assess the safety and efficacy of ABDC inhalation for the treatment of respiratory Candida spp. colonization in critically ill patients.

Methods: All non-neutropenic patients admitted into the intensive care unit (ICU) of a university hospital from December 2010-2011, who had positive Candida spp. cultures of the respiratory tract for more than 1 day and required mechanical ventilation $>48 \mathrm{~h}$ were retrospectively included. The decision to start ABDC inhalation had been made by attending intensivists on clinical grounds in the context of selective decontamination of the digestive tract. Infection characteristics and patient courses were assessed.

Results: Hundred and thirteen consecutive patients were studied. Fifty-one of them received ABDC inhalation and their characteristics at baseline and day 1 of respiratory colonization did not differ from those of colonized patients not receiving treatment $(n=62)$. The ABDC-treated group had a similar Candida spp. load but did not decolonize more rapidly as compared to untreated patients. The clinical pulmonary infection and lung injury scores did not decrease as in the untreated group. In a Cox proportional hazard model, the duration of mechanical ventilation was increased $(P<0.003)$ by ABDC treatment independently of other potential determinants and Candida spp. colonization. No differences in ventilator-associated pneumonia or in overall mortality (up to day 90) were observed. Conclusion: Treatment of respiratory Candida spp. colonization in non-neutropenic critically ill patients by inhaled $A B D C$ may not affect respiratory colonization but may increase duration of mechanical ventilation, because of direct toxicity of the drug on the lung.
\end{abstract}

Keyword: Amphotericin B, Lung injury, Pneumonia, Efficacy, Safety, Mechanical ventilation

\footnotetext{
* Correspondence: p.vandergeest@erasmusmc.nl

${ }^{1}$ Department of Intensive Care Medicine, Erasmus Medical Centre, Gravendijkwal 230, 3015 CE Rotterdam, the Netherlands

Full list of author information is available at the end of the article
} 


\section{Background}

In critically ill patients, Candida spp. are frequently cultured from non-sterile body sites. However, the clinical significance hereof is not easy to define. When Candida spp. are isolated from the respiratory tract, discriminating between relatively harmless colonization or invasive infection is still surrounded by controversy and leads to therapeutic dilemmas [1-8]. On the one hand, respiratory isolation of Candida spp. could reflect the patient's state of immunoparalysis and the elimination of normal flora through previous antibiotic treatment but may otherwise be relatively harmless. On the other hand, it could reflect a risk factor for invasive Candida spp. infections, even in non-neutropenic patients, such as candidemia or pulmonary candidiasis, a rare and difficult to diagnose deep infection in the critically ill $[2,3]$. Respiratory Candida spp. colonization has also been suggested to be a risk factor for (multidrug-resistant) Gram-negative airway infection, i.e. ventilator-associated pneumonia (VAP) or tracheobronchitis, to prolong ventilator dependency and to increase mortality, even in the absence of direct pulmonary pathogenicity [6,9-11].

One way to examine the clinical role of Candida spp. colonization of the respiratory tract is to examine the effect of treatment aimed at eradicating the fungus. The criteria to start antifungal drugs continue to be debated $[1,4]$. Nevertheless, one study suggests that systemic antifungal treatment may help to prevent Pseudomonas spp.associated VAP in the critically ill patient colonized by Candida spp. in the respiratory tract [11]. Also, in neutropenic hematology patients at risk for invasive fungal infections inhalation therapy with liposomal amphotericin B has been proven to prevent invasive pulmonary aspergillosis $[12,13]$. ABDC inhalation is also used to prevent pulmonary aspergillosis in many lung transplant units but the safety and efficacy of this approach has never been validated in a large randomized placebo-controlled trial.

Selective decontamination of the digestive tract (SDD) is a strategy used in many Dutch intensive care units (ICU's) and consists of oral administration of non-absorbable antibiotics. When Candida spp. respiratory colonization is documented during routine surveillance cultures of the respiratory tract and the patient is at risk for deep infection, intensivists often start with amphotericin-B deoxycholate (ABDC) inhalation therapy via a nebulizer. This treatment is started as part of many SDD protocols used in large trials $[14,15]$. However, its safety and efficacy are not well established, in the absence of randomized trials [16]. In rats, aerolized $\mathrm{ABDC}$ decreases activity of surfactant suggesting a possibility to harm [17-19]. In humans, however, (liposomal) amphotericin-B inhalation may not alter surfactant but may be cytotoxic by other means $[20,21]$.

To further elucidate the significance of Candida spp. in respiratory secretions and the safety and efficacy of
ABDC inhalation therapy, we retrospectively compared clinical courses of mechanically ventilated patients colonized with Candida spp. in the respiratory tract which received $A B D C$ inhalation with those of a comparable group of patients in which ABDC was not initiated. The hypothesis was that ABDC is a safe and effective treatment for Candida spp. colonization of the respiratory tract and thereby prevents VAP and prolonged need for mechanical ventilation during SDD in the ICU.

\section{Methods}

\section{Patients}

Data were retrospectively collected from our patient data management system, according to a predefined checklist. All patients $>18$ years of age requiring mechanical ventilation $>48 \mathrm{~h}$ in the ICU of the Erasmus Medical Center Rotterdam, with at least 2 consecutive daily positive Candida spp. cultures of the respiratory tract (throat, tracheal aspirates or bronchoalveolar lavage), defining respiratory colonization, were included when admitted between December 2010 and December 2011. The ICU is a tertiary care mixed medical-surgical ICU with 2000 admissions per year. Patients with neutropenia (leukocyte count $<0.5 \times$ $10^{9} / \mathrm{L}$ ), positive blood cultures for Candida spp., immunodeficiency (HIV, solid cancer, hematologic malignancy, solid- organ or bone marrow transplantation, or long term or high dose steroid treatment) or who did not meet respiratory colonization criteria were excluded (Figure 1). Informed consent was not needed according to the Dutch law because of the retrospective analysis in which data collected during routine clinical care were used and anonymously treated.

\section{Clinical protocol}

Patients requiring mechanical ventilation for more than $48 \mathrm{~h}$ receive SDD in our unit. This involves administration of an oral paste, a suspension via the nasogastric

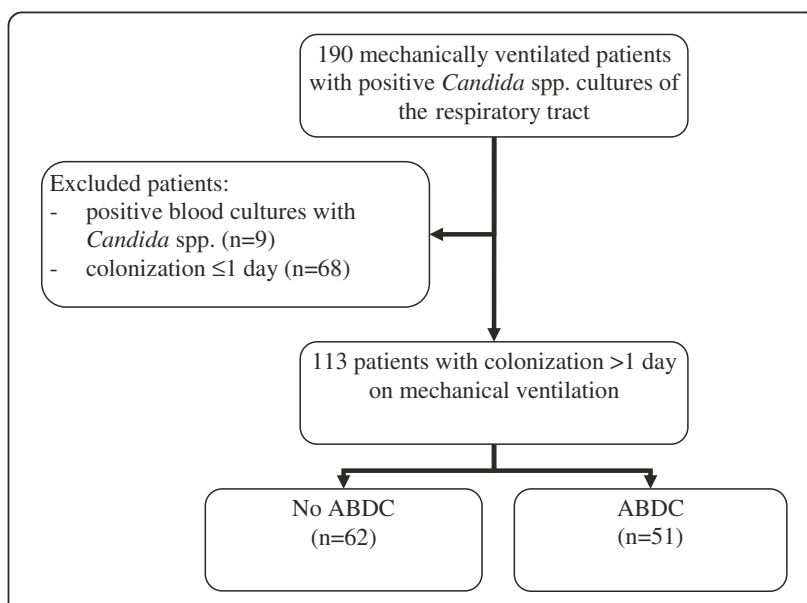

Figure 1 Patient inclusion. $A B D C=$ amphotericin- $B$ deoxycholate. 
tube and a suppository, containing the non- absorbable antibiotics tobramycin, amphotericin B and colistin. For the first three days, patients also receive cefotaxim intravenously at 4 times 1 gram a day. At the start of SDD, cultures are taken (inventory cultures) from throat, tracheal aspirates, urine, rectum and drains or wounds. To monitor the effect of the SDD, surveillance cultures (from throat, tracheal aspirates, urine, and rectum) are done routinely three times per week. SDD and surveillance cultures are continued until ICU death or discharge. On indication, additional cultures of the respiratory tract are taken at the discretion of the attending intensivist. Standard microbiological methods were used to culture the specimens. For the purpose of fungal detection in respiratory samples a Sabouraud agar (SB), incubated at $26^{\circ} \mathrm{C}$ was used. A Gram strain was performed to identify epithelial cells and bacteria. If the Gram strain contained 10 times more leukocytes than epithelial cells and if there were more than 6 species of one type of microorganism the streaked agar plates were incubated. Candida colonies are visually identified on the Sabouraud agar and identified to the species level using CHROMagar ${ }^{\mathrm{rm}}$. ABDC inhalation therapy is not part of the standard of care SDD regimen but can be added at the discretion of the attending intensivist when tracheal aspirates or throat cultures are repeatedly positive for Candida spp. and the patient is considered to be at risk for deep infection. For this purpose ABDC, dissolved in dextrose 5\% with a final concentration of $10 \mathrm{mg} / \mathrm{mL}$ is nebulized in a Maquet nebulizing system (Maquet Servo Ultra Nebulizer, Maquet, Sweden), 4 times daily (daily dose $4 \times 4 \mathrm{~mL}=40 \mathrm{mg}$ ). $\mathrm{ABDC}$ inhalation therapy is discontinued after two consecutive daily respiratory tract cultures or after detubation of the patient. Other antifungal therapy was instituted at the discretion of the attending intensivist based on cultures taken from other body sites. Pneumonia was diagnosed and treated by the attending intensivist on the basis of clinical, imaging and microbiological data in close collaboration with the infectious disease specialists. VAP was defined as the presence of a new or progressive pulmonary infiltrate on the chest radiograph along with infectious signs such as fever $\geq 38.5^{\circ} \mathrm{C}$ or $\leq 36.5^{\circ} \mathrm{C}$, leukocyte count $\geq 10 \times 10^{9} / \mathrm{L}$ or $\leq 4 \times 10^{9} / \mathrm{L}$ and purulent tracheobronchial secretions [22].

\section{Study protocol and data collection}

At admission/baseline, demographic data and clinical variables, including age, sex, pre-morbidity, prior use of antibiotics including SDD and other risk factors for Candida spp. colonization, antifungal treatment, steroids, immune status (active malignancy or other causes of an immunocompromised state), reasons for admission, invasive procedures (arterial or venous central catheter, pulmonary artery catheter, endotracheal intubation) and treatment of organ failure (inotropic support, hemodialysis and mechanical ventilation settings) were recorded (but not all data are shown when considered not contribute). The simplified acute physiology score (SAPS II) was computed at admission. Day 1 of the study was defined as the first day of respiratory colonization with Candida spp. The acute physiology and chronic health evaluation II (APACHE II) and the sequential organ failure assessment (SOFA) were recorded at day 1 . All cultures from the respiratory tract were recorded from day 1 until day of decolonization, i.e. the duration of respiratory colonization. Airway Candida decolonization was defined as the first day of 2 consecutive daily respiratory cultures negative for Candida spp. in the ICU. Candida spp. load was calculated as the number of positive respiratory cultures and the sum of the load (in thousands of colonies) of the cultures divided by the total cultures taken, using cultures from day 1 until decolonization, ICU death or discharge, whatever came first. Candida spp. load was classified as mild, $<10^{4}$, moderate, $10^{4}-10^{5}$, and severe, $>10^{5}$. For the ABDC-treated group, the duration of respiratory colonization and load were calculated from day 1 until start of ABDC and from the start of ABDC until decolonization, ICU death or discharge, whatever came first. In order to calculate the clinical pulmonary infection score (CPIS) [23] at day 1 and 7, routinely obtained temperature $\left({ }^{\circ} \mathrm{C}\right)$, white blood cell count (WBC, $10^{9} / \mathrm{L}$ ), amount of tracheal secretions, chest radiography imaging results and $\mathrm{P}_{\mathrm{a}} \mathrm{O}_{2} / \mathrm{F}_{\mathrm{I}} \mathrm{O}_{2}$ ratio $(\mathrm{kPa})$ were recorded using the worse data recorded during the 24 hours of that day. At day 1 and 7, we also recorded positive end-expiratory pressure (PEEP, $\mathrm{cm} \mathrm{H}_{2} \mathrm{O}$ ), ratio of arterial $\mathrm{PO}_{2}$ to inspiratory $\mathrm{O}_{2}$ fraction $\left(\mathrm{P}_{\mathrm{a}} \mathrm{O}_{2} / \mathrm{F}_{\mathrm{I}} \mathrm{O}_{2}, \mathrm{kPa}\right)$, total respiratory dynamic compliance $\left(\mathrm{mL} / \mathrm{cm} \mathrm{H}_{2} \mathrm{O}\right)$ and chest radiography imaging results to calculate the lung injury score (LIS) [24]. The compliance is calculated from tidal volume and difference between in- and expiratory pressures on the ventilator. The LIS is calculated by using the worst physical data recorded during the 24 hours of that day and the number of quadrants (0-4) on the chest radiograph showing alveolar consolidations. Patients were followed until day 28 and 90 after day 1 and duration of ICU stay, duration of colonization and mechanical ventilation (from day 1 until start of inhalational ABDC and thereafter until detubation not requiring reintubation within $48 \mathrm{~h}$ ) and vital outcomes were recorded.

\section{Statistical analysis}

Continuous variables were expressed as the mean with standard deviation (SD) or when the assumption of normality (Kolmogorov-Smirnov test $\mathrm{P}<0.05$ ) was violated as median values and interquartile ranges. Since ABDC treatment was started at median 5 days of colonization, patients colonized for 5 days or more were selected from the non-treated group for comparisons of durations. Kaplan-Meier curves were constructed and log rank testing was performed to evaluate group differences in 
colonization and ventilation durations, censored for death or discharge from the ICU. Multiple Cox proportional hazard modeling was done to evaluate the effect of ABDC treatment, irrespective of other variables associated with mechanical ventilation. Hazard ratios (HR) and $95 \%$ confidence intervals $(\mathrm{CI})$ were calculated. All tests were two-sided and $\mathrm{P}<0.05$ was considered statistically significant. Exact $\mathrm{P}$ values $>0.001$ are given.

\section{Results}

Characteristics of patients who received ABDC $(n=51)$ and those who did not $(\mathrm{n}=62)$ are summarized in Table 1 .
There tended to be more males in the treated group, but groups were otherwise comparable at baseline up to day 1 , suggesting similar general risks for respiratory Candida spp. colonization. However, ABDC-treated patients had a longer duration of stay in the ICU but mortality did not differ from that in untreated patients.

\section{Respiratory Candida spp. colonization, risk factors, bacterial infection and treatment characteristics according to ABDC inhalation treatment}

Table 2 gives the data from day 1 of respiratory colonization until ICU death or discharge for the untreated and treated

Table 1 Patient characteristics at admission, day 1 of colonization and clinical course

\begin{tabular}{|c|c|c|c|}
\hline & ABDC no $n=62$ & ABDC yes $n=51$ & $\mathbf{P}$ \\
\hline Age, years & $57(17)$ & $58(20) \mathrm{s}$ & 0.62 \\
\hline Gender, male & $34(55)$ & $37(73)$ & 0.05 \\
\hline \multicolumn{4}{|l|}{ Premorbidity } \\
\hline Cardiac & $31(50)$ & $18(35)$ & 0.12 \\
\hline Gastointestinal & $21(34)$ & $24(47)$ & 0.16 \\
\hline Cancer & $17(27)$ & $16(31)$ & 0.65 \\
\hline Pulmonary & $16(26)$ & $13(25)$ & 0.97 \\
\hline Neurological & $11(18)$ & $12(24)$ & 0.45 \\
\hline DM & $12(19)$ & $8(16)$ & 0.61 \\
\hline Renal & $5(8)$ & $9(18)$ & 0.14 \\
\hline Immune & $2(3)$ & $0(0)$ & 0.16 \\
\hline Other & $20(32)$ & $14(27)$ & 0.58 \\
\hline Reasons of ICU admission & & & 0.28 \\
\hline Suspected infection & $18(29)$ & $18(35)$ & \\
\hline Respiratory failure & $9(15)$ & $13(25)$ & \\
\hline Shock & $9(15)$ & $6(12)$ & \\
\hline Neurological & $11(18)$ & $4(8)$ & \\
\hline Medical & $3(5)$ & $3(6)$ & \\
\hline Postoperative & $6(9)$ & $4(8)$ & \\
\hline CPR & $4(6)$ & $1(2)$ & \\
\hline Trauma & $2(3)$ & $2(4)$ & \\
\hline SAPS ॥ & $43(18)$ & $48(16)$ & 0.12 \\
\hline \multicolumn{4}{|l|}{ At day 1 of colonization } \\
\hline APACHE ॥ & $21(12)$ & $20(9)$ & 0.21 \\
\hline SOFA & $9(6)$ & $9(5)$ & 0.18 \\
\hline Days from admission ICU & $1(3)$ & $1(2)$ & 0.64 \\
\hline Ventilation from admission, days & $1(2)$ & $1(3)$ & 0.18 \\
\hline \multicolumn{4}{|l|}{ Course } \\
\hline Duration of stay ICU, days & $10(12)$ & $24(18)$ & $<0.001$ \\
\hline 28-day mortality & $19(32)$ & $10(20)$ & 0.13 \\
\hline 90-day mortality & $27(45)$ & 19 (37) & 0.40 \\
\hline
\end{tabular}

Numbers (percentage) or median (interquartile range), where appropriate. Abbreviations: $A B D C=$ amphotericin-B deoxycholate; $D M=$ diabetes mellitus; $\mathrm{ICU}=$ intensive care unit; $\mathrm{CPR}=$ cardiac pulmonary resuscitation; SAPS $\|=$ simplified acute physiology score; APACHE $\|=$ acute physiology and chronic health evaluation II; SOFA = sequential organ failure assessment score. 
Table 2 Respiratory Candida spp. colonization, risk factors, bacterial infection and treatment characteristics starting day 1 of colonization in untreated group and from day 1 of colonization to start of treatment in treated group and thereafter, until ICU death or discharge

\begin{tabular}{|c|c|c|c|c|c|}
\hline & $\begin{array}{l}\text { ABDC no Day } 1 \text { until ICU death } \\
\text { or discharge, } n=62\end{array}$ & $\begin{array}{l}\text { ABDC yes Day } 1 \text { to start } \\
\text { treatment, } \mathrm{n}=51\end{array}$ & P vs no & $\begin{array}{l}\text { ABDC yes Day } 1 \text { until ICU } \\
\text { death or discharge, } n=51\end{array}$ & P vs no \\
\hline Total Candida spp. cultures respiratory tract 2 (1) & & $3(1)$ & 0.67 & $4(3)$ & $<0.001$ \\
\hline Candida spp. load & & & 0.46 & & 0.36 \\
\hline Mild, $<10^{4}$ & $38(61)$ & $32(58)$ & & $30(60)$ & \\
\hline Moderate, $10^{4}-10^{5}$ & $13(21)$ & $18(33)$ & & $16(32)$ & \\
\hline Heavy, $>10^{5}$ & $11(18)$ & $5(9)$ & & $4(8)$ & \\
\hline Candida albicans & $41(66)$ & $34(61)$ & 0.45 & $32(63)$ & 0.74 \\
\hline Candida non-albicans & $3(4)$ & $1(2)$ & & $3(6)$ & \\
\hline Both Candida spp. & $18(30)$ & $20(37)$ & & $16(31)$ & \\
\hline Duration of respiratory colonization, days & $5(9)$ & $5(5)$ & 0.66 & $12(18)$ & $<0.001$ \\
\hline Corticosteroids & $23(37)$ & $18(35)$ & 0.85 & $22(43)$ & 0.52 \\
\hline TPN & $21(34)$ & $16(31)$ & 0.78 & $18(35)$ & 0.88 \\
\hline Ventilator-associated pneumonia, & $23(37)$ & $11(22)$ & 0.16 & $18(35)$ & 0.96 \\
\hline Days after first Candida spp. culture & $4(6)$ & $3(4)$ & 0.43 & $5(4)$ & 0.91 \\
\hline Gram positive & $6(10)$ & $0(0)$ & & $2(4)$ & \\
\hline Gram negative & $17(27)$ & $11(22)$ & & $16(31)$ & \\
\hline CPIS, day 1 & $7(3)$ & $8(2)$ & 0.10 & NA & NA \\
\hline day 7 & $5(4)$ & NA & NA & $8(3)$ & $<0.001$ \\
\hline Systemic antifungal treatment & $17(27)$ & $13(26)$ & 0.39 & $18(35)$ & 0.93 \\
\hline Echinocandins & $11(17)$ & $9(18)$ & & $11(21)$ & \\
\hline Azoles & $6(10)$ & $4(8)$ & & 7 (14) & \\
\hline
\end{tabular}

Numbers (percentage) or median (interquartile range), where appropriate. Abbreviations: ABDC = amphotericin-B deoxycholate; TPN = total parenteral nutrition; CPIS =clinical pulmonary infection score; day 1 and 7 refer to day of first isolation of Candida spp. in respiratory secretions and 1 week later, respectively; $\mathrm{NA}=$ not applicable. 
groups. Colonization lasted 5 (9) days in the untreated group and ABDC was started 5 (5) days after the day of first positive respiratory Candida spp. culture, so that we also compared groups for these comparable time frames. The data suggest similar risk and load of respiratory colonization with Candida spp. until treatment is started for both groups. However, the ABDC-treated group seemed to have an overall higher load and prolonged colonization than the untreated group, because of start of early and spontaneous decolonization in the latter. The CPIS score was higher 1 week after day 1 in the absence of more VAP in treated patients. Conversely, there was no decrease in the occurrence of VAP in the treated group. Even though total Candida spp. cultures in the respiratory tract after start of ABDC (1 (2)) was lower than before start (3 (1)) (P $<0.001)$, respiratory colonization durations were similar, from day 5 (untreated group) or start of treatment (ABDCtreated group) to 28 days later (Figure 2).

\section{Patient courses}

Table 3 gives the ventilation characteristics for both groups. The LIS and $\mathrm{P}_{\mathrm{a}} \mathrm{O}_{2} / \mathrm{F}_{\mathrm{I}} \mathrm{O}_{2}$ ratio at day 1 were similar between the groups, but at day 7 the LIS was higher and the $\mathrm{P}_{\mathrm{a}} \mathrm{O}_{2} / \mathrm{F}_{\mathrm{I}} \mathrm{O}_{2}$ ratio was lower in the ABDC-treated than untreated group. The PEEP was higher in the ABDC-treated group at day 7. Patients receiving ABDC were mechanically ventilated longer than patients without treatment (Figure 3), from day 5 or start of treatment onwards, in untreated and treated groups, respectively. The effect of ABDC on mechanical ventilation duration was independent from other factors such as duration of colonization after day 5 and LIS on day 7 (Table 4 ).

\section{Discussion}

This non-randomized observational study suggests that ABDC inhalation by critically ill, mechanically ventilated patients with respiratory Candida spp. colonization is not effective and potentially harmful. Patients on ABDC inhalation did not decolonize more rapidly, remained mechanically ventilated for an additional 13 days and had a longer ICU stay but no increased mortality, as compared to untreated patients.

Our study suffers from a non-randomised design, so that conclusions should be drawn carefully. Nevertheless, the data suggest that prior to start of treatment, disease severity, colonization risk and load were similar among the groups. Treatment was started approximately 5 days after the first positive respiratory Candida spp. culture, when in the untreated group spontaneous decolonization had already started. We are therefore uncertain, in disagreement with previous studies [16], whether decolonization would have also occurred in the treated group if treatment had been disadvised or postponed. However, when groups were matched for the same duration of respiratory colonization prior to treatment, no difference could be observed in rate of decolonization (Figure 2), in contrast to the increase in decolonization with treatment from 62 to $86 \%$ observed in a previous, but larger, non-randomized study [16].

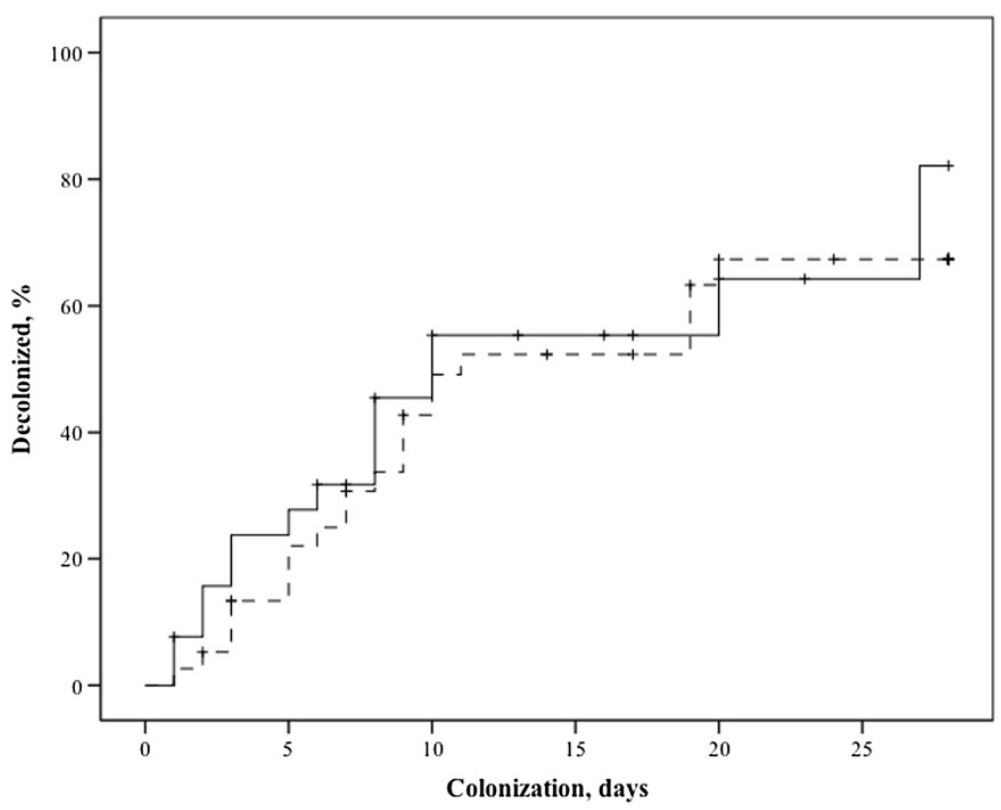

Figure 2 Duration of respiratory colonization from day 5 (now day 0 in graph) of colonization in untreated (continuous line) and from start of amphotericin $B(A B D C)$ on day 0 in graph in treated patients (dotted line) until negative cultures, censored for death or discharge from the intensive care unit, to day $28 ; P=0.45$ (log-rank test). 
Table 3 Ventilation characteristics at day 1 and 7 of colonization

\begin{tabular}{|c|c|c|c|}
\hline & ABDC no $n=62$ & $A B D C$ yes $n=51$ & $\mathbf{P}$ \\
\hline Tidal volume, ml/kg, day 1 & $7(2)$ & $7(2)$ & 0.77 \\
\hline Tidal volume, ml/kg, day 7 & $7(3)$ & $8(3)$ & 0.50 \\
\hline PEEP, $\mathrm{cm} \mathrm{H}_{2} \mathrm{O}$, day 1 & $9(4)$ & $9(4)$ & 0.10 \\
\hline PEEP, cm H $\mathrm{H}_{2} \mathrm{O}$, day 7 & $6(5)$ & $10(6)$ & 0.004 \\
\hline Compliance, $\mathrm{mL} / \mathrm{cm} \mathrm{H}_{2} \mathrm{O}$, day 1 & $37(28)$ & $44(39)$ & 0.05 \\
\hline Compliance, $\mathrm{mL} / \mathrm{cm} \mathrm{H}_{2} \mathrm{O}$, day 7 & $40(27)$ & $41(36)$ & 0.09 \\
\hline $\mathrm{P}_{\mathrm{a}} \mathrm{O}_{2} / \mathrm{F}_{1} \mathrm{O}_{2}$ ratio, day 1 & $213(122)$ & $197(137)$ & 0.40 \\
\hline $\mathrm{P}_{\mathrm{a}} \mathrm{O}_{2} / \mathrm{F}_{1} \mathrm{O}_{2}$ ratio, day 7 & $282(123)$ & $217(147)$ & 0.005 \\
\hline Chest X-ray, no. of quadrants, day 1 & $2(2)$ & $2(1)$ & 0.27 \\
\hline Chest $X$-ray, no. of quadrants, day 7 & $2(3)$ & $2(2)$ & 0.41 \\
\hline LIS, day 1 & $2.0(1.0)$ & $1.8(1.3)$ & 0.47 \\
\hline LIS, day 7 & $1.0(1.3)$ & $1.8(1.5)$ & 0.002 \\
\hline Ventilation after day 1 , days & $7(9)$ & $20(16)$ & $<0.001$ \\
\hline
\end{tabular}

Numbers (percentage) or median (interquartile range), where appropriate. Abbreviations: $\mathrm{ABDC}=$ amphotericin $\mathrm{B}$ deoxycholate; $\mathrm{PEEP}=$ positive end-expiratory pressure; $\mathrm{P}_{\mathrm{a}} \mathrm{O}_{2}=$ partial pressure of oxygen in the blood $(\mathrm{kPa}) ; \mathrm{F}_{1} \mathrm{O}_{2}=$ the percentage of oxygen administered; LIS = lung injury score; day 1 and 7 refer to day of first isolation of Candida spp. in respiratory secretions and 1 week later, respectively.

A previous study showed an incidence of VAP in patients with respiratory Candida spp. colonization of $24 \%$ which is comparable to the $29 \%$ incidence in this study [9]. However, our data do not suggest that Candida spp. colonization in the respiratory tract predisposed to VAP, in contrast to studies suggesting that this could promote VAP development, especially when caused by Pseudomonas aeruginosa and multidrug resistant bacteria $[9,10]$. Conversely, there is no suggestion that respiratory decolonization was associated with less VAP, in contrast to suggestions that systemic antifungal treatment decreases the incidence of VAP [11]. The differences in ventilation durations cannot be attributed to differences in the occurrence of VAP, even though the relatively non-specific CPIS (as well as the LIS) was higher on day 7 in the ABDCtreated group, since the CPIS was not a determinant of mechanical ventilation duration in multivariate analysis.

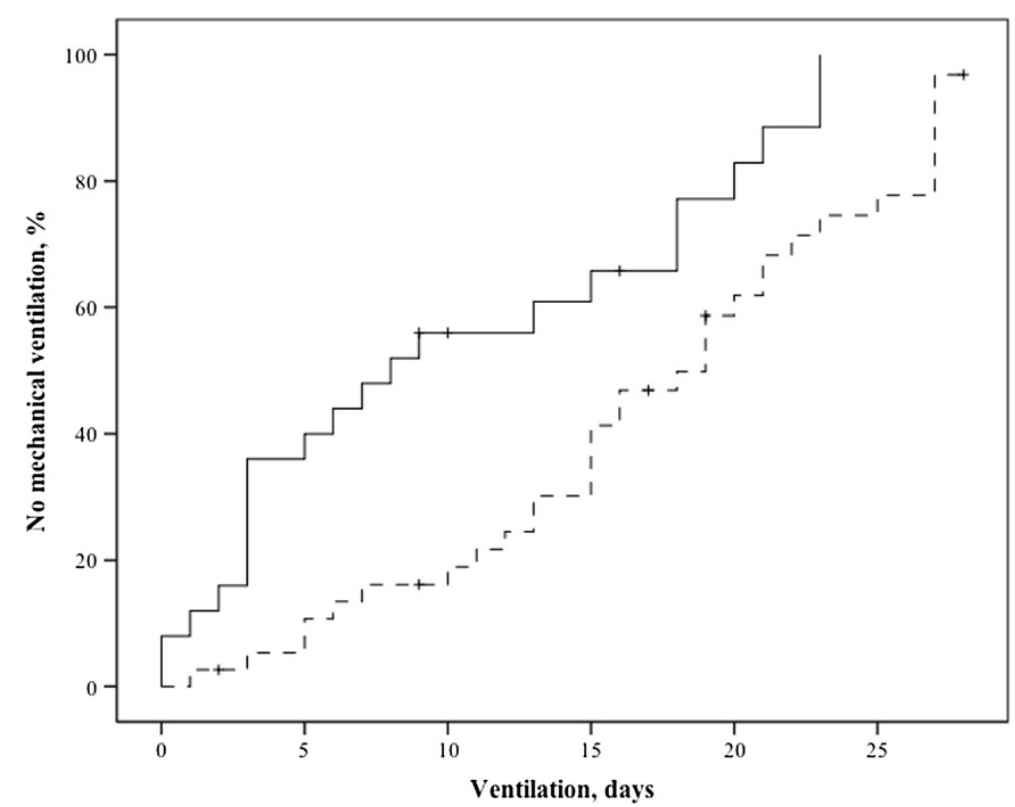

Figure 3 Duration of mechanical ventilation from day 5 (now day 0 in graph) of colonization in untreated (continuous line) and from start of amphotericin $B(A B D C)$ on day 0 in graph in treated patients (dotted line), censored for death or discharge from the intensive care unit, to day $28 ; P=0.003$ (log-rank test). 
Table 4 Multiple Cox proportional hazard modeling for duration of mechanical ventilation

\begin{tabular}{lll}
\hline & HR (95\% Cl) & P \\
\hline ABDC treatment & $3.63(1.57-8.34)$ & 0.003 \\
Candida spp. load until day 5 & $1.19(0.70-2.02)$ & 0.51 \\
Candida spp. load after day 5 & $0.67(0.31-1.47)$ & 0.32 \\
Duration of colonization until day 5 & $0.96(0.90-1.02)$ & 0.13 \\
Duration of colonization after day 5 & $0.92(0.88-0.96)$ & $<0.001$ \\
CPIS day 7 & $0.91(0.76-1.10)$ & 0.32 \\
LIS day 7 & $0.60(0.40-0.91)$ & 0.02 \\
\hline
\end{tabular}

Hazard ratios (HR; $95 \%$ confidence interval, $\mathrm{Cl}$ ) are given for each variable. Abbreviations: $\mathrm{ABDC}=$ amphotericin $\mathrm{B}$ deoxycholate; $\mathrm{CPIS}=$ clinical pulmonary infection score; LIS = lung injury score.

Safety issues of ABDC inhalation therapy remain a concern $[19,20]$. We therefore looked at pulmonary injury and ventilation durations, which appeared independent of respiratory colonization duration in our patients. The lung scores suggest greater injury in treated patients at day 7 already than in untreated patients, independent of VAP. Two studies showed surfactant dysfunction by ABDC, thereby deteriorating gas exchange $[17,18]$, possibly via direct inhibition or damage of the alveolar capillary membrane resulting in an influx of surfactant-inactivating plasma proteins. Loss of surfactant could lead to longer requirement of mechanical ventilation in patients receiving inhalational ABDC. Indeed, the longer duration of mechanical ventilation and thus ICU stay in our study in ABDC-treated patients can be explained by pulmonary adverse effects of the drug. Our data do not exclude that ABDC inhalation prevents pulmonary infections with Aspergillus spp. but suggests that it may carry pulmonary toxicity.

\section{Conclusions}

In conclusion, treatment of pulmonary Candida spp. colonization in non-neutropenic critically ill patients by inhaled $\mathrm{ABDC}$ may not facilitate respiratory decolonization but may increase duration of mechanical ventilation, because of direct pulmonary toxicity of the drug. Therefore, inhalation of $\mathrm{ABDC}$ for respiratory colonization with Candida spp. in non-neutropenic critically ill patients cannot be recommended outside prospective randomized trials. For the latter, the use of less toxic liposomal dissolved formulation may be preferred [21,25].

\section{Ethics}

This study does not need approval from a medical ethical committee for the following reason. Division 1, Section 1.1.b. of the Dutch law on medical research defines medical research as research in which persons are subjected to treatment or are required to follow a certain behavioral strategy (www.ccmo.nl, http://www. ccmo.nl/attachments/files/wmo-engelse-vertaling-29-72013-afkomstig-van-vws.pdf). This means that retrospective patient data analysis is not subject to this law. Indeed, informed consent is not needed, provided that, as we did, data are retrieved and analyzed anonymously.

\section{Competing interests}

The authors declare that they have no competing interests.

\section{Authors' contributions}

$P G, E D$ and $A G$ participated in the design of the study. PG, ED and BR extracted data from the information systems and made the case record forms. Statistical analysis was performed by PG and AG. All authors read and approved the final manuscript.

\section{Author details}

'Department of Intensive Care Medicine, Erasmus Medical Centre, Gravendijkwal 230, 3015 CE Rotterdam, the Netherlands. ${ }^{2}$ Department of Medical Microbiology, Erasmus Medical Centre, Gravendijkwal 230, 3015 CE Rotterdam, the Netherlands.

Received: 7 July 2014 Accepted: 17 October 2014

Published online: 28 October 2014

\section{References}

1. El-Ebiary M, Torres A, Fabregas N, Puig de la Bellacasan J, Gonzalez J, Ramirez J, del Bano D, Hernandez C, Jimenez de Anta MT: Significance of the isolation of candida species from the respiratory samples in critically ill, non-neutropenic patients: an immediate post- mortem histologic study. Am J Respir Crit Care Med 1997, 156:583-590.

2. Rello J, Esandi ME, Diaz E, Mariscal D, Gallego M, Valles J: The role of Candida sp isolated from bronchoscopic samples in nonneutropenic patients. Chest 1998, 14:146-149.

3. Charles PE, Dalle F, Doise JM, Quenot JP, Aho LS, Chavanet P, Blettery B: Candida spp. colonization significance in critically ill medical patients; a prospective study. Intensive Care Med 2005, 31:393-400.

4. Eggimann P, Calandra T, Fluckiger U, Bille J, Garbino J, Glauser MP, Marchetti $\mathrm{O}$, Ruef C, Tauber M, Pittet D: Invasive candidiasis: comparison of management choices by infectious disease and critical care specialists. Intensive Care Med 2005, 31:1514-1521.

5. León C, Ruiz-Santana S, Saavedra P, Almirante B, Nolla-Salas J, Alvarez-Lerma F, Garnacho-Montero J, Leon MA: A bedside scoring system ("Candida score") for early antifungal treatment in nonneutropenic critically ill patients with Candida colonization. Crit Care Med 2006, 34:730-737.

6. Delisle M-S, Williamson DR, Perreault MM, Albert M, Jiang X, Heyland DK: The clinical significance of Candida colonization of respiratory tract secretions in critically ill patients. J Crit Care 2008, 23:11-17.

7. Meersseman W, Lagrou K, Spriet I, Maertens J, Verbeken E, Peetermans WE, Van Wijngaarden E: Significance of the isolation of Candida species from airway samples in critically ill patients: a prospective, autopsy study. Intensive Care Med 2009, 35:1526-1531.

8. Cornely OA, Bassetti M, Calandra T, Garbino J, Kullberg BJ, Lortholary O, Meersseman W, Akova M, Arendrup MC, Arikan-Akdagli S, Bille J, Castagnola E, Cuenca-Estrella M, Donnelly JP, Groll AH, Herbrecht R, Hope WW, Jensen HE, Lass-Flörl C, Petrikkos G, Richardson MD, Roilides E, Verweij PE, Viscoli C, Ullmann AJ: ESCMID guideline for the diagnosis and management of Candida diseases 2012: non-neutropenic adult patients. Clin Microbial Infect 2012, 18:19-37.

9. Azoulay E, Timsit JF, Tafflet M, de Lassence A, Darmon M, Zahar JR, Adrie C, Garrouste-Orgeas M, Cohen Y, Mourvillier B, Schlemmer B: Candida colonization of the respiratory tract and subsequent Pseudomonas ventilator- associated pneumonia. Chest 2006, 129:110-117.

10. Hamet M, Pavon A, Dalle F, Pechinot A, Prin S, Quenot JP, Charles PE: Candida spp. airway colonization could promote antibiotic resistant bacteria selection in patients with suspected ventilator associated pneumonia. Intensive Care Med 2012, 138:1272-1279.

11. Nseir S, Jozefowicz E, Cavestri B, Senid B, Di Pompeo C, Dewayrin F, Favory $R$, Roussel-Delvallez $M$, Durocher A: Impact of antifungal treatment on 
Candida-Pseudomonas interaction: a preliminary retrospective casecontrol study. Intensive Care Med 2007, 33:137-142.

12. Rijnders BJ, Cornelissen JJ, Slobbe L, Becker MJ, Doorduijn JK, Hop WC, Ruijgrok EJ, Lowenberg B, Vulto A, Lugtenburg PJ, de Marie S: Aerolized liposomal amphotericin $B$ for the prevention of invasive pulmonary aspergillosis during prolonged neutropenia: a randomized placebo controlled trial. Clin Infect Dis 2008, 46:1401-1408.

13. Kuiper $L$, Ruijgrok EJ: A review on the clinical use of inhaled amphotericin B. J Aerosol Med Pulm Drug Del 2009, 22:213-227.

14. De Jonge E, Schultz MJ, Spanjaard L, Bossuyt PMM, Vroom MB, Dankert J, Kesecioglu J: Effects of selective decontamination of digestive tract on mortality and acquisition of resistant bacteria in intensive care: a randomised controlled trial. The Lancet 2003, 362:1011-1016.

15. De Smet AM, Kluytmans JA, Cooper BS, Mascini EM, Benus RF, van der Werf TS, van der Hoeven JG, Pickkers P, Bogaers-Hofman D, van der Meer NJ, Bernards AT, Kuijper EJ, Joore JC, Leverstein-van Hall MA, Bindels AJ, Jansz AR, Wesselink RM, de Jongh BM, Dennesen PJ, van Asselt GJ, te Velde LF, Frenay IH, Kaasjager K, Bosch FH, van Iterson M, Thijsen SF, Kluge GH, Pauw W, de Vries JW, Kaan $\mathrm{JA}$, et al: Decontamination of the digestive tract and oropharynx in ICU patients. N Eng/ J Med 2009, 360:20-31.

16. Ong DS, Klein Klouwenberg P, Spitoni C, Bonten MJ, Cremer OL: Nebulised amphotericin B to eradicate Candida colonisation from the respiratory tract in critically ill patients receiving selective digestive decontamination: a cohort study. Crit Care 2013, 17:R233.

17. Van t' Veen A, Gommers D, Mouton JW, Kluytmans JA, Krijt EJ, Lachmann B: Exogenous pulmonary surfactant as a drug delivering agent: influence of antibiotics on surfactant activity. Br J Pharmacol 1996, 118:593-598.

18. Ruijgrok EJ, Vulto AG, Van Etten WM: Efficacy of aerosolized amphotericin $B$ desoxycholate and liposomal amphotericin B in the treatment of invasive pulmonary aspergillosis in severely immunocompromized rats. J Antimicrob Chemother 2001, 48:89-95.

19. Knechtel SA, Klepser ME: Safety of aerolized amphotericin B. Expert Opin Drug Saf 2007, 6:523-532.

20. Fauvel M, Farrugia C, Tsapis N, Gueuti C, Cabaret O, Bories C, Bretagne S, Barratt G Aerosolized liposomal amphotericin B: prediction of lung deposition, in vitro uptake and cytotoxicity. Int J Pharm 2012, 436:106-110.

21. Monforte V, López-Sánchez A, Zurbano F, Usseti P, Sole A, Casals C, Cifrian J, de Pablos A, Bravo C, Roman A: Prophylaxis with nebulized liposomal amphotericin B for Aspergillus infection in lung transplant patients does not cause changes in the lipid content of pulmonary surfactant. $J$ Heart Lung Transplant 2013, 32:313-319.

22. Grgurich PE, Hudcova J, Lei Y, Sarwar A, Craven DE: Diagnosis of ventilatorassociated pneumonia: controversies and working toward a gold standard. Curr Opin Infect Dis 2013, 26:140-150

23. Rosbolt MB, Sterling ES, Fahy BG: The utility of the clinical pulmonary infection score. J Intensive Care Med 2009, 24:26-34.

24. Murray JF, Matthay MA, Luce JM, Flick MR: An expanded definition of the adult respiratory distress syndrome. Am Rev Respir Dis 1988, 138:720-723.

25. Hamil RJ: Amphotericin B, formulations: a comparison review of efficacy and toxicity. Drugs 2013, 73:919-934.

doi:10.1186/s12879-014-0575-3

Cite this article as: van der Geest et al:: Safety and efficacy of amphotericin-B deoxycholate inhalation in critically ill patients with respiratory Candida spp. colonization: a retrospective analysis. BMC Infectious Diseases 2014 14:575.

\section{Submit your next manuscript to BioMed Central and take full advantage of:}

- Convenient online submission

- Thorough peer review

- No space constraints or color figure charges

- Immediate publication on acceptance

- Inclusion in PubMed, CAS, Scopus and Google Scholar

- Research which is freely available for redistribution
C Biomed Central 